\title{
MAHMUD YUNUS DAN PEMIKIRANNYA DALAM PENDIDIKAN
}

\author{
Oleh: Zulmardi*
}

\begin{abstract}
As an innovator in educational thought in Indonesia, Mabmud Yunus has pioneered several innovated works. Among his innovated thoughts in education, especially in terms of educational institution are: grading the education levels in accordance with the age of pupils, establishing PGA (senior high schools for Islamic teaching teacher training), and ADIA (Academy of Islamic Studies) in Jakarta. In terms of teaching methods, Mahmud Yunus pioneered the application of Directs Methods (thariqal al- mubasyarab), in teaching Arabic. On of his important ideas deal with the nation that "methods of instruction are more important than that of material" (al thariqatu ahammu min al maddah). In curriculum field, he has already applied integrated curriculum which integrates knowledge in general sense and Islamic one.
\end{abstract}

Kata Kunci: pemikiran, pendidikan

\section{PENDAHULUAN}

$\mathrm{B}$ anyak tokoh pendidikan Islam di Sumatera Barat yang berjasa dalam pengembangan Institusi pendidikan Islam, sebut saja H.M. Thabib Umar, Syekh Ibrahim Musa Parabek dengan Sumatera Thawalibnya, Rahmah El Yunusiah dengan Diniyah Putrinya. Prof. Dr. H. Mahmud Yunus dengan Normal Islamnya, Abdul Ahmad dengan Adabiyah Schoolnya dan banyak lagi yang lainnya. Makalah ini akan mengemukakan salah satu tokoh tersebut, yaitu Prof. Dr. H. Mahmud Yunus tentang riwayat hidup, hasil karyanya dan konsep pemikirannya tentang pendidikan.

\section{PENDIDIKAN ISLAM DI MINANG- KABAU SEBELUM MAHMUD YUNUS}

Sebelum lahirnya madrasah, lembaga pendidikan Islam di Minangkabau yang terkenal adalah surau. Kelihatannya di masa dulu fenomena pesantren yang demikian berkembang di pulau Jawa tidak banyak mempengaruhi pertumbuhan dan perkembangan lembaga pendidikan Islam semacam ini di Minangkabau, sekurangnya sampai terjadi modernisasi dalam pesantren belakangan ini.

Jika surau disebut sebagai suatu lembaga pendidikan Islam semacam pesantren, itu tidak lain disebabkan terdapatnya beberapa karakteristiknya yang sama atau mirip dengan pesantren. Meskipun demikian, perbedaan-perbedaan antara surau dengan pesantren terutama dalam hubungannya dengan kedudukan "Syekh" (kiyainya surau) dengan kiyai dalam pesantren di pulau Jawa. Lingkungan sosio kultural dan keagamaan di Minangkabau syarat dengan proses-proses dan dinamika yang terjadi dalam masyarakat ini mempengaruhi pula kedudukan syekh sebagai figur

* Penulis adalah Lektor dalam Mata Kuliah Pengembangan Kurikulum pada STAIN Batusangkar 
utama pada suatu surau dan untuk selanjutnya juga mempengaruhi eksistensi surau itu sendiri.

Mesjid menduduki tempat penting dalam struktur sosial dan keagamaan masyarakat Minangkabau. Karena itu surau yang merupakan semacam mesjid dalam ukuran lebih kecil juga mempunyai kedudukan penting, meskipun fungsinya itulah kemudian dapat dilihat perbedaan surau di Minangkabau dengan langgar di Pulau Jawa.

Menurut Sidi Gazalba (1983) surau merupakan bangunan peninggalan kebudayaan masyarakat setempat sebelum datangnya Islam. Surau dalam sistem adat Minangkabau adalah kepunyaan kaum, suku atau individu, ia didirikan oleh suatu kaum tertentu sebagai bangunan rumah gadang, di mana berdiam beberapa keluarga yang sapariuak, saparuik di bawah pimpinan seorang datuk.

Kehadiran surau sebagai sebuah lembaga pendidikan Islam semacam pesantren jelas berkaitan erat dengan perluasan fungsi surau dalam masyarakat Minangkabau. Cikal bakal surau dalam kontek pembicaraan terakhir ini setidaktidaknya menurut Mahmud Yunus (1979) pertama kali dimunculkan oleh Syekh Burhanuddin (1066 - 1111 H/ 1646 - 1691). Sekembalinya dari Kotaraja Aceh di mana dia belajar ilmu agama pada Syekh Abdurrauf Singkel ia mendirikan surau di kampung halamannya Ulakan Pariaman. Di surau inilah Syekh Burhanuddin melakukan pengajaran Islam dan mendidik beberapa murid yang menjadi ulama yang berperan dalam pengembangan ajaran Islam selanjutnya di Minangkabau.

Metode utama yang digunakan dalam belajar mengajar di surau adalah ceramah dan resitasi. Pelajaran disampaikan secara lisan kepada muridmurid yang duduk dalam satu lingkaran di depan syekh. Metode pengajaran ini disebut "halaqah", atau mungkin semacam metode "bandongan"(Prasidjo, 1982) di pesantren di Jawa.

Materi pelajaran sepenuhnya ditentukan syekh disesuaikan dengan umur dan kemampuan masing-masing orang siak. Pelajaran yang diberikan pada tingkat dasar antara lain membaca Alquran dengan berbagai qiraatnya, ibadah, dasar-dasar ilmu tauhid dan lain-lain. Sedangkan untuk orang siak yang telah cukup dewasa diberikan pula pelajaran tasauf dan tarikat.

Pelajaran pada umumnya disampaikan oleh syekh sendiri tetapi karena jumlah orang siak sudah sedemikian banyak, maka syekh mengangkat beberapa "guru tuo" untuk membantunya. Para guru tuo ini selain memberikan penjelasan lebih rinci mengenai mata pelajaran, juga bertugas mengawasi orang siak dalam menghafal pelajaran yang diterimanya. Menurut Mahmud Yunus, pendidikan Islam pada waktu itu berada dalam kemunduran. Hal itu disebabkan terutama karena semua daerah Minangkabau dikuasai Belanda dan banyak Syekh yang meninggal karena terlibat dalam Perang Padri.

Situasi surau yang demikian itu ditambah tekanan-tekanan kolonial Belanda terhadap masyarakat Minangkabau mendorong timbulnya keinginan sebagian kalangan agama untuk mengirimkan anak-anaknya belajar ke tanah suci. Seperti dicatat Hamka, anak-anak dan keturunan kaum agama yang nenek moyangnya terlibat langsung atau tidak langsung dengan gerakan Padera dikirim orangtuanya belajar ke Mekkah. Arus penuntut ilmu ke tanah suci ini lebih dimungkinkan sejak kapal api telah menggantikan kapal layar sehingga perjalanan ke tanah suci menjadi lancar.

Kebanyakan putra Minangkabau di tanah suci belajar pada Syekh Ahmad Khatib, ulama asal Minangkabau yang telah lama menetap dan berkeluarga di 
Mekkah. Murid-murid Syekh Ahmad Khatib yang kemudian menjadi ulama yang terkemuka antara lain: Syekh Abdul Ahmad, Syekh Muhammad Jamil Jambek, Syekh Abdul Karim Amrullah, Syekh Muhammad Thaib Umar, Syekh Daud Rasyidi, Syekh Ibrahim Musa dan lain-lainnya.

Sejak awal abad 20 masyarakat Islam Minangkabau berada dalam situasi yang semakin terjepit. Pada satu pihak, ia menghadapi tekanan-tekanan ekonomi dan politik yang semakin berat dari kolonial Belanda, sedangkan di pihak lain ide-ide pembaharuan keagamaan dalam segenap aspeknya semakin gencar pula gaungnya. Gebrakan kaum muda ulama yang baru kembali dari Mekkah semakin gencar ketika Minangkabau memasuki dekade kedua abad 20. Mereka banyak dipengaruhi oleh gagasan pembaruan Muhammad Abduh (Nasution, 1973). Mereka menyerukan kepada umat untuk kembali kepada Alquran dan Sunnah dengan menghilangkan sikap taqlid (Asshiddiqi, 1971) terhadap ajaran ulama atau mazhab tertentu. Keimanan atas dasar taqlid menurut mereka adalah tidak benar, keimanan hendaklah disertai dengan penggunaan akal untuk melakukan ijtihad.

Kaum muda semakin ekspansif dalam menerapkan gagasan-gagasannya. Mereka mulai mendirikan sekolahsekolah agama yang telah dimodernisasi baik sistem metode maupun kurikulumnya. Pengajaran bukan lagi berlangsung di surau tetapi sudah di kelas. Pengajaran bukan lagi "halaqah" tetapi klasikal dengan tingkatan-tingkatan kelas. Pembaharuan seperti ini dilakukan agar guruguru agama dan kaum ulama dibekali ilmu dan alat untuk menghadapi tantangan kebutuhan zaman. Karenanya ilmu pengetahuan umum dan bahasa Arab (Belanda dan Inggris) dimasukkan dalam kurikulum. Metode terbaik untuk mencapai kemajuan ekonomi dan pendidikan menurut mereka adalah melalui organisasi-organisasi sosial. Karena itu berbagai organisasi sosial yang terutama bergerak dalam pembaruan pendidikan agama didirikan oleh kaum muda. Tahun 1914 Syekh Abdullah Ahmad memprakarsai berdirinya "Syarikat Oesaha" di Padang. Usaha pertama mendirikan HIS Adabiah tanggal 23 Agustus 1915 yang menjadi HIR pertama di Minangkabau yang memasukkan pelajaran agama di dalam kurikulum. Tahun 1918 berdiri pula perkumpulan Sumatera Thawalib yang mendirikan sekolah-sekolah agama di Padang Panjang, Parabek, Padang Japang, Batusangkar, Maninjau, Bukittinggi dan lain-lain. Sumatera Thawalib inilah menerbitkan majalah-majalah kaum muda. Selanjutnya tahun 1920 organisasi persatuan guru-guru agama Islam. Sementara itu di Padang Panjang Zainuddin Labai El Yunusi mendirikan Diniyah School pada tanggal 10 Oktober 1915 kemudian adiknya Rahmah El Yunusiah mendirikan pula Diniyah School Puteri tanggal 1 Nopember 1923.

\section{RIWAYAT HIDUP MAHMUD YUNUS}

Prof. Dr. H. Mahmud Yunus lahir di Sungayang Batusangkar pada hari Sabtu 10 Februari 1899 (30 Ramadhan 1316). Ayahnya bernama Yunus bin Incek dan ibunya bernama Hafsah binti M. Thahir. Buyutnya dari pihak ibu adalah seorang ulama besar di Sungayang Batusangkar bernama M. Ali gelar Angku Kolok.

Riwayat pendidikan Mahmud Yunus dimulai mempelajari Alquran dan Bahasa Arab yang ia tempuh semenjak berusia tujuh tahun di surau kakeknya M. Thahir, di samping itu ia juga memasuki sekolah rakyat, tetapi hanya sampai kelas tiga. Dari surau kakeknya ini ia pindah ke madrasah yang diasuh 
oleh Syekh H.M. Thaib Umar di surau Tanjung Pauh. Berkat ketekunannya dalam waktu empat tahun Mahmud Yunus telah sanggup mengajarkan kitab Mahalli, Alfiyah dan Jam'u al Jawami'. Oleh sebab itu ketika Syekh H.M Thaib Umar sakit dan berhenti mengajar, maka yang ditunjuk sebagai penggantinya adalah Mahmud Yunus. Pada tahun 1917 Mahmud Yunus bersama-sama temantemannya mengajar di Madrasah School mulai memperbaharui sistem kegiatan belajar mengajar dengan menambah sistem Halaqah (belajar secara melingkar di sekitar guru) di samping sistem madrasah dengan mengajarkan kitabkitab mutakhir.

Di sela-sela kesibukannya sebagai guru Mahmud Yunus menghadiri rapatrapat besar alim ulama seluruh Minangkabau tahun 1919 (mewakili Syekh H.M Thaib pendiri madrasah). Dalam musyawarah tersebut diputuskan untuk mendirikan PGAI (Persatuan Guru Agama Islam) Mahmud Yunus termasuk salah satu anggotanya. Mahmud Yunus juga ikut memprakarsai berdirinya perkumpulan pelajar-pelajar Islam Batusangkar dengan nama "Sumatera Thawalib" tahun 1920. Perkumpulan ini berhasil menerbitkan majalah Islam yang bernama Al-Basyir di bawah asuhan Mahmud Yunus. Dengan kegiatan-kegiatannya Mahmud Yunus termotivasi untuk melanjutkan studinya ke Mesir, namun niatnya gagal karena tidak memperoleh visa dari konsul Inggris. Karena kegagalannya ini Mahmud Yunus mengintensifkan dirinya menulis buku-buku di samping mengajar. Ketekunan tersebut menghasilkan karya monumental dari Mahmud Yunus dengan berhasilnya menulis tafsir Alquran yang tetap populer sampai saat ini. Penulisan tafsir ini dimulai tahun 1922 yang dilakukan secara berangsur-angsur juz demi juz sampai selesai juz ke 30 .
Pada tahun 1924 Mahmud Yunus mendapat kesempatan untuk melanjutkan pendidikan ke Mesir Universitas AlAzhar. Setahun kemudian ia memperoleh Shahadah Aliyah. Kemudian ia melanjutkan studinya ke Madrasah Darul Ulum Al-Ulya Cairo dan tercatat sebagai mahasiswa pertama dari Indonesia. Tahun 1930 setelah mengambil spesialisasi Tadris, akhirnya Mahmud Yunus berhasil memperoleh ijazah Tadris dari perguruan tersebut.

Dengan dua ijazah yang dimilikinya bakatnya sebagai seorang guru betul-betul teraplikasi, hal ini terbukti dengan kemampuannya memimpin sekolah-sekolah di samping mengajar, seperti Sekolah Al-Jami'ah Al-Islamiyah Batusangkar (1931-1932). Kuliah Muallimin Normal Islam Padang Tahun 19321946. Akademi Pamong Praja di Bukittinggi tahun 1948-1949. Akademi Dinas Ilmu Agama (ADIA) Jakarta tahun 1957-1980, menjadi Dekan dan Guru Besar pada Fakultas Tarbiyah IAIN Syarif Hidayatullah Jakarta tahun 19601963. Rektor IAIN Imam Bonjol Padang tahun 1966-1971. Atas jasa-jasanya di bidang pendidikan ini IAIN Syarif Hidayatullah Jakarta menganugrahkan Mahmud Yunus Doktor Honoris Causa dalam ilmu Tarbiyah.

Di samping pendiri organisasi Sumatera Thawalib, PGAI dan penerbit Majalah Al-Basyir ia juga menjadi anggota Raad Minangkabau tahun 19381942, dalam hal ini Mahmud Yunus berhasil memasukkan pendidikan agama Islam di sekolah pemerintah. Ia juga menjadi anggota Pemeriksa Agama pada Jawatan Pengajaran Agama Sumatera Barat. Kepada Bagian Islam pada Jawatan Agama Propinsi Sumatera di Pematang Siantar 1946-1949. Mahmud Yunus ikut mendirikan Majlis Islam Tinggi Minangkabau yang kemudian menjadi MIT Sumatera tahun 1946 menjadi Inspektur Agama pada Jawatan 
PP\&K Propinsi Sumatera berkedudukan di Bukittinggi tahun 1947 dan pernah pula dipercaya sebagai sekretaris Menteri Agama PDRI 1949.

\section{HASIL KARYA MAHMUD YUNUS}

Mahmud Yunus adalah penulis yang cukup produktif. Banyak bukunya telah diterbitkan dan tersebar di tanah air. Buku-buku tersebut meliputi berbagai bidang ilmu, di antaranya bidang pendidikan, hukum Islam(fiqh), tafsir, akhlak, ilmu jiwa, sejarah Islam dan lain-lain. Bukunya itu antara lain:

\section{Bidang Pendidikan}

Sejarah Pendidikan Islam di Indonesia (Penerbit Mutiara Jakarta, 1997), Pendidikan di Negara-negara Islam dan Intisari Pendidikan Barat (CV. Al-Hidayah Jakarta, 1968), Pengetahuan Umum dan Ilmu Mendidik: Methodik Khusus Pendidikan Agama (PT. Hidakarya Agung Jakarta, 1980), Pengembangan Pendidikan Islam di Indonesia; Pokok-pokok Pendidikan dan Pengajaran (PT. Hidakarya Agung Jakarta, 1978), Al-Tarbiyah wal-Ta'lim (Pendidikan dan Pengajaran).

\section{Bidang Bahasa Arab Diantaranya}

Pelajaran Bahasa Arab I, Pelajaran Bahasa Arab II, Pelajaran Bahasa Arab III, Pelajaran Bahasa Arab IV, Durus Al-Lughat Methodik Khusus Bahasa Arab: Kamus Arab-Indonesia: Contoh Tulisan Arab, (17) Muthall'ah wa Mahfuzhar (Bedah Buku dan Kata Mutiara): Darus Al-Lughat al-'Arabiyah II (PT. Hidakarya Agung Jakarta, 1980): Durus Al-Lughat Al-Arabiyah III (PT. Hidakarya Agung Jakarta, 1980): Muhadatsat Al-Arabiyah/ Percakapan: Bahasa Arab (PT. Hidakarya Agung Jakarta, 1981): Al-Muktarat Lil-
Muthalla'ah wal-Mahfuzhat (Kapita Selekta Bedah Buku dan Kata Mutiara).

\section{Bidang Fiqh (Hukum Islam) Bukunya Antara lain:}

Marilah Sembahyang I (Hidakarya Agung, Jakarta, 1979), Marilah Sembahyang II (Hidakarya Agung Jakarta, 1979), Puasa dan Zakat (Hidakarya Agung Jakarta, 1979), Haji ke Mekkah (Hidakarya Agung Jakarta, 1979), Hukum Warisan dalam Islam (Hidakarya Agung, Jakarta 1974), Hukum Perkawinan dalam Islam 4 Mazhab (Hidakarya Agung, Jakarta, 1979), Pelajaran Sembahyang untuk Orang Dewasa: Soal Jawab Hukum Islam: Fiqh Al-Wadhih I: Al-Fiqh Al-Wadhih II (Hidakarya Agung, Jakarta, 1935), Al-Fiqh AlWadhih III (Hidakarya Agung Jakarta, 1936), Mabadi' al-Fiqh Al-Tsanawiy: Tarikh Al-Fiqh Al-Islamiy (Sejarah Fiqh Islam), Al-Masail Al-Fiqhiyah 'ala Madzahib Al-Arab'ah (Masalah-masalah Fiqh Empat Madzhab).

\section{Bidang Tafsir Bukunya Meliputi:}

Tafsir Alquran Karim $30 \mathrm{Juz}$ Tafsir Al-Fatihah (Sa'adiyah Putra, Padang Panjang-Jakarta, 1971),Tafsir Ayat Akhlak (Al Hidayah Jakarta, 1975), Juz 'Amma dan Terjemahnya (Hidakarya Agung, Jakarta, 1978), Tafsir Alquran Juz 1-10, Pelajaran Huruf Alquran I-II, 1973: Kesimpulan Isi Alquran, Tahun 1978, Alif Ba-Ta wa Juz 'Amma Muhadharat Al-Israiliyat fi Tafsir wal-Hadits (Cerita Israiliyat dalam tafsir dan hadist), Tafsir Alquran Karim Juz II-20, 1973, Tafsir Alquran Karim juz 21-30, 1973, Kamus Alquran I: Kamus Alquran II Kamus Alquran Juz 1-30 (Hidakarya Agung Jakarta, 1978: Surat Yasin dan Terjemahannya 1977).

Bidang Akhlak bukunya antara lain: 
Keimanan dan Akhlak I (1979):

Keimanan dan Akhlak II (1979):

Keimanan dan Akhlak III (1979):

Keimanan dan Akhlak II (1979):

Beriman dan Berbudi Pekerti

(Hidakarya Agung, Jakarta 1981): Lagulagu Baru Pendidikan Agamal Akhlak Bahasa Indonesia: Moral Pembangunan dalam Islam: Akhlak (1978).

\section{Bidang Sejarah Islam bukunya antara lain:}

Sejarah Islam di Minangkabau tahun 1971: Tarikh Al-Islam (Hidakarya Agung, Jakarta, 1971).

\section{Bidang Perbandingan Agama}

Ilmu Perbandingan Agama (Hidakarya Agung, Jakarta, 1978), Al-Adyan (agama-agama).

Bidang Dakwah bukunya antara lain:

Pedoman Dakwah Islamiyah (Hidakarya Agung, Jakarta, 1978)

Bidang Ushul Fiqh bukunya antara lain:

Mudzakarat ushul Al-Fiqh

Bidang Tauhid bukunya antara lain:

Durus Al-Tauhid (pelajaran tauhid)

Bidang Ilmu Jiwa bukunya antara lain:

Ilmu i-Nafsi (ilmu jiwa)

\section{Buku Tentang Doa seperti:}

$\begin{array}{ccc}\text { Kumpulan } & \text { Do'a } & \text { (Hidakarya } \\ \text { Agung Jakarta, 1976), Doa-doa }\end{array}$ Rasulullah (Hidakarya Agung, Jakarta 1979).

\section{Buku tentang Pemikiran}

a. Mari Kembali ke Alquran (Hidakarya Agung Jakarta, 1971) b. Al-Syuhur Al-Arabiyah fi l-Bilad AlIslamiyah

\section{Buku tentang Kisah}

Beberapa Kisah Nabi dan Khalifahnya (Hidakarya Agung, Jakarta, 1980), Khulashah Tarikh Hayat AlUstadz Mahmud Yunus (Ringkasan Biografi Mahmud Yunus).

Buku tentang Pelajaran Agama antara lain

Pemimpin Pelajaran Agama I: Pemimpin Pelajaran Agama II: Pemimpin Pelajaran Agama III (AlHidayah Jakarta).

\section{PEMIKIRAN MAHMUD YUNUS TENTANG PENDIDIKAN}

Mahmud Yunus telah mengeluarkan ide-ide pembaharuan pendidikan di lembaga yang dipimpinnya antara lain dalam aspek kelembagaan, aspek metode dan sistem pendidikan serta aspek tujuan dan kurikulum. Untuk lebih jelasnya ketiga aspek tersebut dapat dijelaskan:

\section{Aspek Kelembagaan}

Pada aspek ini Mahmud Yunus mendirikan sekolah Al-Jami'ah AlIslamiyah dan Normal Islam di Padang, setelah ia pulang kuliah dari Mesir tahun 1931. Pada kedua sekolah ini Mahmud Yunus telah melaksanakan penjenjangan pendidikan berdasarkan usia siswa (yang sebelumnya tidak dilakukan penjenjangan sehingga peserta didik beragam usinya). Program pendidikan dilakukan berlangsung selama 12 tahun dengan jenjang pendidikan sebagai berikut:

a. Jenjang Ibtidaiyah 4 tahun

b. Jenjang Tsanawiyah 4 tahun 
c. Jenjang Aliyah 4 tahun

Sistem penjenjangan ini dilakukannya hampir bersamaan dengan jenjang pendidikan di Al-Azhar dan Darul Ulum.

Dalam pembaruan lembaga yang dipimpinnya dibuktikan dengan adanya sikap keterbukaan dalam hal membolehkan siswa yang belajar di sekolahnya dari mana saja asalkan beragama Islam. Kondisi saat ini sangat berbeda sekali dengan sekolah yang didirikan oleh Penjajah Belanda yang diskriminatif dalam perekrutan siswa. Politik pengajaran kolonial pada waktu itu terjadinya perbedaan sekolah untuk anak-anak bumi putera yang disebut dengan sekolah rendah bumi putra adalah HIS dengan anak-anak Belanda yang sekolahnya disebut ELS (Europascha Lagere School).

Dengan adanya diskriminasi oleh kolonial Belanda tersebut jelas tidak semua anak-anak bumi putra dapat sekolah yang menyebabkan anak-anak tersebut mengalami kebodohan. Karena itu dua sekolah Mahmud Yunus yang didirikannya itu menerima anak-anak pribumi dalam menimba ilmu pengetahuan dan membina kepribadian generasi muda.

Pada kedua sekolah inilah Mahmud Yunus memadukan ilmu agama dengan ilmu umum. Madrasah Normal Islam nilah pertama kali memiliki laboratorium untuk ilmu Fisika dan Kimia di Sumatera Barat.

Dengan keberhasilannya memimpin kedua madrasah ini Mahmud Yunus bermaksud untuk mendirikan Sekolah Tinggi Islam di Padang dan terwujud pada tanggal 1 Nopember 1940, akan tetapi pada 1 Maret 1942 Sekolah Tinggi Islam tersebut terpaksa ditutup karena Jepang tidak mengizinkanya.

Selanjutnya berdasarkan jabatan yang dia pegang Mahmud Yunus terpanggil pula untuk melakukan pem- benahan-pembenahan dalam pengelolaan pendidikan. Dia mendirikan SGHA di Kota Raja Bukittinggi dan Bandung serta mendirikan PGA di 8 Kota.

Pembaharuan pada aspek lembaga pendidikan lainnya Mahmud Yunus berhasil mengadakan pelajaran agama di sekolah-sekolah negeri (umum) ketika ia memegang jabatan Kepala Bagian Islam pada jawatan Agama Propinsi Sumatera Barat yang diajukan PPK (Kanwil P\&K sekarang) mulai dari SD hingga SMA.

Pada tanggal 1 Januari 1951 Mahmud Yunus dipercaya KH. Abdul Wahid Hasyim (menteri agama waktu itu) wakil menjadi kepala penghubung pendidikan Agama pada Departemen Agama di Jakarta. Dalam jabatan ini di bawah pimpinan Departemen Agama waktu itu telah mengeluarkan beberapa ketetapan:

a. Mewujudkan peraturan bersama menteri P\&K dan menteri Agama tentang pendidikan agama di sekolahsekolah swasta.

b. Mendirikan pendidikan guru agama (PGA) pada tahun 1951 di 8 kota: Tanjung Pinang, Kota Raja, Bukittinggi, Banjarmasin, Jakarta, Tanjung Karang, Bandung dan Pemekasan.

c. Menetapkan rencana pendidikan agama Islam di sekolah-sekolah dasar dari kelas empat sampai enam, di sekolah menengah, untuk mewujudkan peraturan bersama Menlu PPK dan Menteri Agama tentang peraturan Perguruan Tinggi Agama Islam Negeri (PTAIN) di Yogyakarta, kemudian Mahmud Yunus mendirikan Akademi Dinas Ilmu Agama (ADIA) di Jakarta, ia juga menjadi Dekan di lembaga ini dan mengusulkan ke Menteri Agama agar ADIA dapat menjadi sebuah perguruan tinggi yang dapat mengeluarkan sarjana penuh.

\section{Aspek metode dan sistem pendidikan}


Metode adalah salah satu komponen dalampembelajaran. Metode berarti cara atau jalan yang dijalani untuk dilalui dalam mencapai tujuan pendidikan. Dalam pendidikan Islam banyak metode yang digunakan seperti metode keteladanan, nasehat, memberikan pujian, peringatan dan hukuman, bercerita, latihan kebiasaan, menyalurkan bakat dalam waktu singkat. Mahmud Yunus juga menggunakan metode ini dalam proses belajar mengajar tentu saja penggunaannya disesuaikan dengan tingkat pertumbuhan dan pengembangan anak didik.

Setelah satu metode yang sering digunakan Mahmud Yunus khususnya pengajaran bahasa Arab adalah metode langsung (thariqah al-mubasyarah) yaitu suatu metode yang secara langsung mewajibkan siswa-siswanya bercakapcakap dalam bahasa Arab. Metode all in one system artinya seluruh cabang ilmu bahasa Arab diajarkan secara integral sampai mempraktekkan dalam percakapan harian. Metode ini merupakan khas pengajaran bahasa Arab di Al-Jami alIslamiyah dan Normal Islam, di bandingkan dengan lembaga-lembaga pendidikan Islam lain yang ada pada ketika itu. Dalam pemikiran Mahmud Yunus jika di sekolah-sekolah swasta bahasa Belanda dijadikan sebagai pengantar maka tidaklah salah jika di madrasah bahasa Arab pun bisa dijadikan bahasa pengantar dalam mempelajari ilmu agama dan ilmu lainnya. Untuk hal tersebut Mahmud Yunus telah mengarang buku pedoman bahasa arab Durusul Lughah Arabiyah empat jilid saat dia belajar di Mesir. Setelah ia kembali dari Mesir tahun 1931 Mahmud Yunus merealisasikan konsep pengajaran bahasa Arab di kedua madrasah taljami' al-Islamiyah dan Normal Islam yang diberi nama Kulliyatul Muallimin Al-Islamiyah dan Normal Islam Padang sebagai manifestasi dari Darul Ulum di Mesir.
Menurut Mahmud Yunus, metode lebih penting dari materi (al-tariqah ahammu min al-maddat). Katanya metode adalah jalan yang akan ditempuh oleh guru untuk menyampaikan materi pelajaran, jalan itu adalah Khittah (garis) yang direncanakan sebelum masuk ke dalam kelas. Oleh sebab itu seorang guru harus menggunakan metode yang efektif dan efisiensi sehingga tidak melelahkan dan membosankan serta beragam dalam penggunaannya. Lebih lanjut ia menjelaskan banyak guru yang menguasai materi, namun mereka kesulitan dalam menyampaikannya. Oleh sebab itu menurutnya seorang guru harus pandai memilih dan menguasai metode yang digunakannya dan mampu mendorong murid berpikir bukan hanya hafalan.

Dalam menerapkan metode pada suatu mata pelajaran Mahmud Yunus sangat memperhatikan aspek psikologis siswa sesuai dengan prinsip pertumbuhan dan perkembangan anak, ia juga menekankan pentingnya penanaman moral dalam proses belajar mengajar, konsep yang disosialisasikannya itu mencakup ketiga ranah tujuan pendidikan kognitif, afektif dan psikomotor. Aspek kognitif terlihat dalam kegiatan belajar mengajar yang menekankan pada pendalaman materi sehingga anak menjadi kritis, aspek psikomotor dalam kegiatan belajar mengajar menekankan pada pengembangan semaksimal mungkin kecakapan murid sehingga ia terampil dalam mempraktekkan ilmunya dan aspek afektif dalam kegiatan belajar mengajar ia tekankan bagaimana guru mampu menanamkan moral pada murid.

Ketika Mahmud Yunus memperkenalkan Kulliatul Mua'llimin al Islamiyah (KMI) tahun 1931, pelaksanaan pengajaran dilakukan di kelas-kelas dengan jadwal dan kurikulum yang sudah ditetapkan. Jenjang kelas pun diatur, yakni kelas satu sampai kelas enam, setingkat dengan SD/ SLTP. Kitab-kitab 
lama diganti dengan bahan-bahan yang sudah diolah sesuai dengan silabus, di antaranya berupa buku atau diktat yang ditulis oleh Mahmud Yunus. Pelajaran umum dimasukkan seimbang dengan pelajaran agama. Murid-murid diharuskan berbicara dengan bahasa Arab.

Dari uraian di atas tampaklah bahwa metode dan sistem pendidikan seperti ini merupakan perubahan secara drastis, artinya dengan dimasukkannya pelajaran umum dalam kurikulum, adanya laboratorium untuk praktek ilmu fisika dan kimia serta dijadikannya bahasa Arab dan Belanda sebagai bahasa pengantar dan dengan tidak meninggalkan pelajaran agama dengan mempelajari kitab-kitab kuni yang telah dikemas sedemikian rupa sesuai dengan tingkat jenjang pendidikannya merupakan inovasi yang dipelopori oleh Mahmud Yunus.

Untuk mewujudkan hasil yang maksimal Mahmud Yunus mewajibkan siswanya untuk tinggal di asrama yang telah disiapkan oleh PGAI agar siswa terdidik dan mempunyai kedisiplinan yang tinggi selama menempuh pendidikan di Normal Islam.

\section{Aspek Tujuan dan Kurikulum Pen- didikan}

Menurut Mahmud Yunus tujuan pendidikan Islam adalah (a) untuk kecerdasan perorangan (b) untuk kecakapan mengerjakan pekerjaan dengan kata lain tujuan pendidikan Islam itu menyiapkan anak didik agar di waktu dewasa kelak mereka cakap melakukan pekerjaan dunia dan akhirat sehingga tercipta kebahagiaan bersama dunia akhirat.

Agar anak-anak bahagia di akhirat maka harus diajarkan tentang keimanan, akhlak, ibadah dan isi-isi Alquran yang berhubungan dengan hal-hal yang wajib dan haram dan lain-lainnya. Tetapi yang lebih utama dari itu semua adalah pen- didikan akhlak sebab Rasulullah diutus ke dunia ini adalah untuk memperbaiki budi pekerti umatnya. Untuk mencapai kebahagiaan di dunia anak-anak harus diajarkan berbagai macam profesi seperti bertani, berdagang, bertukang, menjadi guru dan lain-lainnya sesuai dengan bakat dan minat anak.

Dari aspek kurikulum pandangan dan berwawasan Mahmud Yunus pada saat itu yang tergolong baru adalah yang berkaitan dengan kurikulum bahasa Arab, bahwa pengajaran bahasa Arab itu dilakukan secara integral dari cabangcabang ilmu bahasa Arab dengan tidak memisah-misahkannya satu persatu, seperti mengajarkan muthala'ah di dalamnya juga dibahas tentang qawaid, insyak, qira'ah dan lainnya dari cabang ilmu bahasa Arab.

Untuk penerapan kurikulum bahasa Arabnya tersebut Mahmud Yunus telah mengarang buku pelajaran bahasa Arab sebanyak 4 jilid. Dalam buku tersebut Mahmud Yunus menerapkan metode pengajaran bahasa Arab dengan memadukan unsur membaca, menulis, memahami dan bercerita dengan menggunakan bahasa Arab. Buku yang dikarangnya pada saat ia berada di Mesir itu mulai ia laksanakan pada tahun 1931 ketika mengajar di Madrasah Al-Jami'ah Al-Islamiyah (1931-1932) dan Normal Islam (1931-1946) yang diberi nama Kulliyatul Al-Muallimin al-Islamiyah Normal Islam Padang.

Mahmud Yunus menambahkan dalam kurikulum Nasional Islam dan AlJami'ah Al-Islamiyah ilmu-ilmu umum, seperti ilmu alam/ kimia, ilmu hayat/ biologi, ilmu pasti/ aljabar dan ilmu ukur, ekonomi, sejarah, ilmu falak, tata negara, bahasa Inggris, bahasa Belanda, gerak badan, ilmu pendidikan, ilmu jiwa, ilmu kesehatan dan khat. Pelajaran bahasa Arab lebih ditekankan pada penguasaan kosa kata, sehingga kelas satu sudah diajarkan mengarang dengan 
bahasa Arab dengan perbendaharaan kata yang dimiliki siswa. Begitu pula pelajaran Muthola'ah (membaca), mahfhuzah (menghafal), qawaid (nahwu, saraf) dan adabullughah, telah diajarkan di kelas satu, demikian pula dengan bahasa Inggris dan bahasa Belanda.

\section{PENUTUP}

Dari uraian yang terdahulu dapat disimpulkan bahwa Mahmud Yunus dapat dikelompokkan sebagai pembaharu dalam pendidikan Islam di Indonesia. Hal ini terlihat dari pendidikan dan gagasannya dalam melakukan perombakan sistem pendidikan Islam yang ketika itu masih tradisional.

Pemikiran Mahmud Yunus dapat dilihat dari ketiga aspek pembaharuannya yaitu; dalam aspek kelembagaan, aspek metode dan sistem pendidikan serta aspek tujuan pendidikan Islam dan kurikulum.

Pada aspek kelembagaan inovasinya adalah adanya penjenjangan program pendidikan yang dipraktekkannya pada Al-Jami'ah Al-Islamiyah yaitu jenjang Ibtidaiyah 4 tahun, Tsanawiyah 4 tahun dan Aliyah 4 tahun, yaitu suatu jenjang yang hampir sama dengan jenjang di Al-Azhar dan Dar Al-Ulum.

\section{DAFTAR PUSTAKA}

Abuddin Nata, 2005. Tokoh-tokoh Pembaharuan Pendidikan Islam di Indonesia, Jakarta: Radja Grafindo Persada,

Didin Syafrudin, 1995 Mahmud Yunus wa Ijtihaadhu fi Tajdid Ta'lim alLughah al-Arabiyah, Jakarta: Studia Islamika, Vol. 2 No. 3

Hamka, 1992. Adat Minangkabau Menghadapi Revolusi, Jakarta: Tekad, Harun Nasution,
Begitu juga di Normal Islam dan Kulliyatul Mua'allimin Al-Islamiyah.

Pada aspek metode Mahmud Yunus melakukan metode yang bervariasi dengan menggunakan sistem klasikal. Dia mempelopori penggunaan metode all in one system dan thariqah al mubasyarah dalam pengajaran bahasa Arab. Selanjutnya dalam hal tujuan beliau memiliki tujuan ganda agar setelah dewasa anak mampu mempersiapkan anak hidup di dunia dan amal ibadah untuk akhirat sehingga mereka menikmati kehidupan di dunia dan akhirat.

Sedangkan dalam aspek kurikulum, beliau telah menetapkan kurikulum terpadu, yaitu antara pengetahuan agama dan pengetahuan umum. Dapat dikatakan bahwa ide-ide tersebut merupakan indikator dari pembaruan konsepnya tentang pendidikan.

Sebagai seorang ahli pendidikan Islam, konsep-konsep pendidikan Mahmud Yunus sangat komprehensif, karena sebagai seorang ahli dan praktisi pendidikan, ia juga seorang pejabat Departemen Agama yang selalu berpikir tentang kemajuan pendidikan Islam. Dengan demikian konsep-konsep pendidikan Mahmud Yunus selalu berangkat dari idealitas empiris.

\section{Ensiklopedi Islam Indonesia, Jakarta: Djambatan}

Harun Nasution, 1975. Pembaharuan dalam Islam; Sejarah Pemikiran dan Gerakan, Jakarta: Bulan Bintang,

Mahmud Yunus dan Kasim Bakri, 1986 Al-Tarbiyah wa al-Ta'lim, Ponorogo: Pondok Moderen Gontor. 
Mahmud Yunus, 1995. Pokok-pokok Pendidikan dan Pengajaran, Jakarta: Hidakarya Agung, ,1979. Sejarah Pendidikan Islam di Indonesia, Jakarta: Mutiara

Ramayulis, Mahmud Yunus dan Pemikirannya tentang Pendidikan, (Hasil Penelitian tidak diterbitkan)

Sidi Gazalba, 1983. Mesjid Pusat Ibadah dan Kebudayaan Islam, Jakarta: Pustaka Antara
Sudjoko Prasidjo et.el., 1982. Profil Pesantren, Jakarta: LP3ES

Suhartono, 1994.Sejarah Pergerakan Nasional, Yogyakarta: Pustaka Pelajar

TM. Hasybi As-Shiddiqy, 1971. Sejarah Pertumbuhan dan Perkembangan Hukum Islam, Jakarta: Bulan Bintang 